\title{
El legado de Ernesto Laclau a las ciencias sociales y humanas*
}

\author{
Hernán Fair ${ }^{1}$ \\ Centro de Investigaciones en Economía y Sociedad \\ en la Argentina Contemporánea (Argentina)
}

En memoria de Ernesto Laclau

Referencia formato APA: Fair, H. (2014). El legado de Ernesto Laclau a las ciencias sociales y humanas. Revista Cientifica Guillermo de Ockham, $12(2), 119-122$.

\section{Resumen}

El presente ensayo examina de forma sucinta algunos de los ejes centrales del legado teórico y político de la obra de Ernesto Laclau a las ciencias sociales y humanas. Destaca, en ese marco, una serie de aportes fundamentales de su teoría política y social para el desarrollo del pensamiento político posfundacional y el análisis sociopolítico y crítico.

Palabras clave: Legado teórico, teoría política contemporánea, pensamiento político posfundacional, análisis sociopolítico y crítico

\section{The legacy of Ernesto Laclau social sciences and humanities}

\section{Abstract}

This paper examines some central axis from theoretical and political legacy of Laclau's work to Social Sciences and Humanities. In this context, highlights some fundamental contributions from his political and social theory to the development of post-foundational political thought and socio-political and critical analysis.

Keywords: Theoretical legacy, contemporary political theory, post-foundational political thought, socio-political and critical analysis

* Este ensayo se inscribe en el marco del Seminario permanente Hegemonía y discurso, que el autor coordina en el centro IESAC-UNQ, bajo el auspicio y financiamiento científico del CONICET.

1. Doctor en Ciencias Sociales en la Universidad de Buenos Aires (UBA). Investigador del Consejo Nacional de Investigaciones Científicas y Técnicas (CONICET-Universidad Nacional de Quilmes). Docente de la UBA y de UNQ. Ha escrito diversos artículos y ensayos sobre la teoría política del discurso de Ernesto Laclau y aplicado sus principales categorías al análisis del menemismo durante la elaboración de su tesis de maestría (Flacso, 2007) y de doctorado (UBA, 2013). E-mail: herfair@hotmail.com 


\section{Introducción}

El reciente fallecimiento del pensador argentino Ernesto Laclau (1935-2014) representa una gran pérdida intelectual y política de lo que ha constituido una de las figuras más importantes e influyentes de la teoría política contemporánea de la segunda mitad del siglo XX. En este breve ensayo de homenaje a su enorme legado, que no desconoce su ferviente militancia política e histórica a favor de las causas populares y emancipadoras, procuraremos sintetizar algunos de sus principales aportes teóricos al pensamiento político posfundacional y al análisis sociopolítico y crítico.

Aunque la extensa obra de Laclau se remonta a los textos de los años setenta, en este ensayo nos concentraremos en las contribuciones que se inician a mediados de la década de los ochenta con el texto Tesis acerca de la forma hegemónica de la política (1985) y el más difundido Hegemonía y estrategia socialista (del mismo ańo y escrito en compañía de Chantal Mouffe). El motivo de esta elección se debe a que la aparición de esos trabajos marca una ruptura teórica y onto-epistemológica de Laclau con la perspectiva neomarxista, que da comienzo a la elaboración de una innovadora teoría posestructuralista de la hegemonía, autodefinida como posmarxista.

\section{Algunas contribuciones teóricas de la obra de Ernesto Laclau}

\section{La deconstrucción del marxismo en clave posgramsciana y la complejización de la tradición posestructuralista}

La obra de Laclau merece ser reconocida como una innovadora y original apuesta teórica y política, que reformuló y complejizó el marxismo y el posestructuralismo, incorporando a la escuela francesa algunas contribuciones del célebre pensador italiano Antonio Gramsci, en clave posfundacional, junto al abordaje interdisciplinario de herramientas de la retórica, la fenomenología y la filosofía posanalítica. En ese marco, debemos destacar el uso "postmarxista" del concepto gramsciano de hegemonía, articulado de forma innovadora con aportes teóricos y conceptuales provenientes de referentes clave del posestructuralismo, como Althusser, Derrida, Foucault, Lefort, Heidegger, De Manel, el psicoanálisis lacaniano y la segunda etapa de la obra de Wittgenstein, entre otros.

\section{La teoría de la democracia radical y plural}

En el marco de la reformulación ideológica que se inició con sus trabajos fundacionales de mediados de los años ochenta, un segundo aporte central de Laclau a la teoría política contemporánea se encuentra en la innovadora combinación de herramientas provenientes de diversas tradiciones culturales, entre ellas el socialismo, el liberalismo político, la concepción clásica de la democracia y el humanismo, que contribuyeron a la elaboración de lo que el pensador argentino definió como una democracia "radical y plural". Esta propuesta, influenciada por aportes de la izquierda nacional argentina (en particular, las interpretaciones de Abelardo Ramos) y del socialismo democrático y humanista italiano (Coletti, Della Volpe), buscó complejizar -aunque desde una visión post-estructuralista- los problemas que tempranamente observó Laclau en las experiencias del socialismo "realmente existente" (básicamente, en la Unión Soviética) y las particularidades que asumió el populismo clásico latinoamericano (cardenismo, peronismo, varguismo). En ese marco, debemos subrayar sus contribuciones para integrar al pensamiento de izquierda posfundacional algunos valores democrático-radicales del liberalismo político, aunque evitando caer en la estrecha visión procedimentalista y formalista del liberalismo democrático y en la concepción antipopular y antinacional que asumió gran parte del socialismo latinoamericano realmente existente (incluido el socialismo argentino). Durante los años noventa y al compás del derrumbe del "socialismo" soviético, el giro político e ideológico de las variantes de la socialdemocracia europea (en particular, el "laborismo" de Tony Blair y el "socialismo" de Felipe González y de Mitterrand) hacia las ideas ortodoxas del Consenso de Washington y el desvanecimiento de las construcciones sustantivas de la democracia en pos de una visión consensualista y formal, Laclau extendería las críticas a las "desviaciones" ideológicas de lo que se conocería como la "tercera vía".

\section{La teoría discursiva de las identidades políticas y la forma hegemónica de la política}

Como un tercer aporte central, debemos destacar el legado intelectual de Laclau para la elaboración de lo que podemos denominar como una teoría postfundacional de las identidades políticas o una teoría discursiva de las identidades, en clave postfundacional. En ese marco, debemos subrayar su novedosa concepción discursiva de las identidades políticas y el énfasis en la triple dimensión antagónica, articulatoria y polémica (en disputa) de lo social. Trascendiendo las clásicas disyunciones binarias entre las visiones objetivistas y subjetivistas, empiristas e idealistas y universalistas y particularistas, Laclau enfatizaría en la dimensión hegemónica de la política vinculada 
a la construcción simbólica y parcial de las identidades y en el carácter político de la realidad social. La operación hegemónica, como capacidad de edificar una universalización parcial del orden social, caracterizada por una lógica articulatoria y una ontología de la precariedad, contingencia y particularidad relativa, le permitirá al teórico argentino trascender los límites de las visiones universalistas y esencialistas, aunque evitando caer en el particularismo relativista de la filosofía posmoderna radical.

\section{La resignificación herética del concepto de populismo}

En el marco de sus aportes para construir una teoría política posfundacional, no podemos dejar de destacar su más reciente revalorización herética del concepto de populismo como una lógica política no peyorativa ni necesariamente negativa, que se vincula a una forma democrático-popular de construir las identidades políticas. En ese contexto, debemos subrayar sus aportes para repensar el papel central de los liderazgos políticos en la construcción discursiva del pueblo y su capacidad de rearticular demandas sociales insatisfechas. Además, en un innovador aporte frente a las tradicionales críticas del posestructuralismo a la metafísica de la presencia, debemos mencionar las contribuciones teóricas tendientes a autonomizar relativamente el papel de los representados, cuyas demandas sociales insatisfechas, para que el líder sea representativo, deben ser tenidas en cuenta de algún modo, más allá de la distancia estructural entre las decisiones políticas que toma el representante y el lugar que ocupan los representados, que pone en evidencia la imposibilidad de una presencia plena.

La teoría discursiva del populismo, pese a mantener una excesiva formalidad y relegar el desarrollo de la dimensión pluralista-liberal de los textos de los años ochenta, no deja de constituir un avance notable en la teoría democrática posfundacional, al plantear una crítica a la histórica denigración del neoliberalismo hacia los fenómenos populares (cardenismo, peronismo, varguismo, chavismo, kirchnerismo, etc.) y al enfatizar en la dimensión política inherente a las visiones que se presentan como tecnocráticas, consensualistas, racionalistas y puramente gestionarias, que rechazan la existencia de antagonismos que son constitutivos del orden social, asumiendo de esta manera una visión neoconservadora, elitista, clientelista y burocrática del proceso de representación política.

\section{El desarrollo de una ontología política de lo social}

La obra de Laclau ha aportado herramientas fundamentales para el desarrollo de una ontología política de lo social por efecto del discurso. En ese marco, a partir de una novedosa perspectiva autodefinida como posmarxista, Laclau retomó y radicalizó contribuciones clave del pensamiento político posfundacional (la sobredeterminación discursiva de lo social, los antagonismos y el poder como constitutivos, la doble dimensión política y simbólica que instituye, sedimenta y reactiva lo social), para elevarlos al rango de postulados ontológicos de la teoría política del discurso.

\section{El arsenal de herramientas teóricas para el análisis sociopolítico y crítico}

Uno de los aspectos más valorables y reconocidos de la obra de Laclau lo constituye el arsenal de categorías que nos ha legado para el análisis sociopolítico y crítico. Entre los aportes más relevantes, podemos destacar los siguientes elementos:

a. La reconceptualización del significante hegemonía, en clave posgramsciana, que ha contribuido a comprender, explicar y criticar las formas de institución político-ideológicas de lo social y a enfatizar en la doble dimensión articulatoria y antagónica de los procesos políticos.

b. El empleo del concepto levistraussiano-lacaniano de "significante vacío" para analizar la forma de construcción discursiva de las hegemonías en la modernidad.

c. Las categorías de cadenas equivalenciales y de fronteras de exclusión y el análisis del papel central de las figuras retóricas, que permiten radicalizar aportes previos de la escuela francesa, reconduciéndolas a la teoría política posfundacional y contribuyendo al desarrollo de lo que ha sido definido como el análisis político del discurso.

d. El innovador uso de algunos conceptos de la retórica y de la teoría lacaniana para el desarrollo del análisis político del discurso y la construcción de hegemonías.

e. En el marco del empleo del psicoanálisis lacaniano desde la teoría política, el papel crucial que asume la dimensión del afecto y las formas de identificación catexiales en torno a los liderazgos políticos, en lo que ha constituido una feroz crítica a las teorías racionalistas que predominan en las ciencias sociales.

f. El uso posfundacional de algunas categorías de la fenomenología, como la sedimentación y la reactivación, para analizar el modo de estructuración precario y transitorio de las identidades políticas y de la realidad social. 


\section{A modo de conclusión}

La fundamental e indispensable obra del pensador argentino Ernesto Laclau contiene una riqueza, complejidad y profundidad tales que podemos ubicarlo -y seguramente así será reconocido en los tiempos venideros- como un verdadero clásico de las ciencias sociales y humanas, referencia ineludible y central de la teoría y la filosofía política contemporáneas y el análisis sociopolítico y crítico. El presente ensayo buscó rescatar algunas de sus más importantes contribuciones, que han sido y continúan siendo difundidas, debatidas, aplicadas y criticadas por referentes teóricos, pensadores y analistas políticos de todo el planeta. Su inmenso legado, sin lugar a dudas, está destinado a perdurar por los siglos y a seguir haciéndonos pensar (en) la política, no solo para comprender y explicar aspectos centrales de la compleja realidad social, sino y sobre todo, para criticar las circunstancias del presente y transformar radicalmente la realidad en un sentido emancipador.

\section{Algunas lecturas recomendadas}

Stavenhagen, R., Laclau, E., \& Marini, R. M. (1973). Tres ensayos sobre América Latina. Anagrama: Buenos Aires.

Laclau, E. (1977). Política e ideología en la teoría marxista. Capitalismo, fascismo, populismo. Siglo XXI: España.

Laclau, E., \& Mouffe, C. (1987). Hegemonía y estrategia socialista. Hacia una radicalización de la democracia. Siglo XXI: Madrid-España.

Laclau, E. (1990). Nuevas reflexiones sobre la revolución de nuestro tiempo. Ediciones Nueva Visión: Buenos Aires.

Laclau, E. (1996). Emancipación y diferencia. Ariel: Buenos Aires.

Laclau, E. (1998). Deconstrucción, Pragmatismo y Hegemonía en C. Mouffe (comp.), Deconstrucción y Pragmatismo, (pp. 97-136). Paidós: Buenos Aires.

Laclau, E. (2005). La razón populista. Fondo de Cultura Económica: Buenos Aires.

Laclau, E. (2008). Debates y combates: por un nuevo horizonte de la política. Fundación de Cultura Económica: Buenos Aires. 